\title{
RETINOPATHY IN NEWLY DIAGNOSED ELDERLY HYPERTENSIVE PATIENTS (>60 YEARS) IN A RURAL TEACHING INSTITUTE OF SUB-HIMALAYAN REGION
}

\begin{tabular}{ll} 
Äbhimanyu Patial & MD Medicine, Medical Officer, Community Health Centre Dheera, Kangra. \\
\hline Akshay Sharma* & $\begin{array}{l}\text { MD Medicine, Medical Officer, Civil hospital Baijnath, Kangra. } \\
{ }^{*} \text { Corresponding Author }\end{array}$ \\
\hline Priya Dhora & $\begin{array}{l}\text { MBBS, Junior Resident, Department of Pathology, Dr Rajendra Prasad Govt. } \\
\text { Medical College, Kangra at Tanda. }\end{array}$ \\
\hline \hline
\end{tabular}

ABSTRACT Introduction: Hypertensive retinopathy is among the vascular complications of essential hypertension. It is known that the auto-regulation of retinal circulation fails as blood pressure increases beyond a critical limit. There is a paucity of data of retinopathy in newly diagnosed elderly hypertensive patients ( $>60$ years) in India. Aim: To assess retinopathy in newly diagnosed elderly hypertensive patients ( $>60$ years) at Dr RPGMC Kangra at Tanda. Methods: One hundred patients above 60 year of age newly diagnosed with hypertension and presenting to outpatient clinic of Department of Medicine, Dr RPGMC Kangra were included. Statistical analysis was performed using SPSS v21.0 (IBM, USA). Results: $30 \%$ patients had retinopathy; $21 \%$ had hypertensive retinopathy ( $5 \%$ grade $1,12 \%$ grade 2 , and $4 \%$ grade 3 ) while $9 \%$ had bilateral non-proliferative diabetic retinopathy (NPDR) with hypertensive retinopathy. Age, sex, BMI, diet, smoking and alcohol consumption were not associated with retinopathy. There was a significant higher number of retinopathy patients were diabetic ( $11 / 30$ vs. $8 / 70 ; \mathrm{P}=0.003)$. There were a significantly higher proportion of retinopathy in patients with chronic kidney disease $(\mathrm{P}=0.003)$. There were a significant number of patients with dyslipidemia among retinopathy patients $(\mathrm{P}<0.05)$. Increasing stage of hypertension was associated with retinopathy. Conclusion: This study proved a definite association between dyslipidemia, diabetes, and CKD and hypertension with retinopathy in newly diagnosed elderly hypertensive patients.

\section{KEYWORDS : Hypertension, dyslipidemia, chronic kidney disease}

INTRODUCTION

Hypertension is a worldwide problem that affects up to 50 million people in the United States and approximately one billion worldwide, and is the single most important modifiable risk factor for stroke. ${ }^{1-3}$ Even milder degrees of blood pressure elevation pose increased risk for cardiovascular events. Unfortunately, hypertension awareness, treatment, and control remain less than optimal. ${ }^{4,5}$ Hypertension acts as a silent killer many years before overt end organ damage is clinically apparent.

Poorly controlled hypertension (HTN) affects several systems such as the cardiovascular, renal, cerebrovascular, and retina. The damage to these systems is known as target-organ damage (TOD) ${ }^{6}$ HTN affects the eye causing 3 types of ocular damage: choroidopathy, retinopathy, and optic neuropathy. ${ }^{7}$ Hypertensive retinopathy (HR) occurs when the retinal vessels get damaged due to elevated blood pressure. There has been significant evidence that hypertensive retinopathy acts as a predictor of systemic morbidity and mortality due to TOD. ${ }^{6} \mathrm{~A}$ study by Erden et al. showed that the increase in the incidence of retinopathy is related to the degree of severity and duration of HTN.

Prevalence of this condition is quite variable, depending of the selection groups, suggesting a range between $12 \%-30 \%$, being more common in the elderly and among females. ${ }^{9}$ However, there is a paucity of data of retinopathy in newly diagnosed elderly hypertensive patients ( $>60$ years) in India. Hence, this study aimed to assess retinopathy in newly diagnosed elderly hypertensive patients (>60 years) at $\mathrm{Dr}$ RPGMC Kangra at Tanda.

\section{METHODS}

This descriptive hospital-based study was conducted in Dr. Rajendra Prasad Government Medical College, hospital Kangra at Tanda over a period of 12 months. All patients above 60 year of age newly diagnosed with hypertension and presenting to outpatient clinic were included. The patients aged below 60 years of age, failure to give consent, nonhypertensive patients, and those failed to complete the work- up, were excluded.

The classification of hypertension was based on the average of two or more properly measured seated BP readings. In JNC 7 , the report JNC in contrast to the classification provided in the JNC 6 report, a new category designated pre-hypertension has been added, and stages 2 and 3 hypertension have been combined. The auscultatory method of BP measurement with a properly calibrated LED apparatus was used. Patients were seated quietly for at least 5 minutes in a chair (rather than on an exam table), with feet on the floor, and arm supported at heart level. Measurement of BP in the standing position was indicated periodically, especially in those at risk for postural hypotension. No liquor intake or smoking before recording blood pressure. An appropriate-sized cuff (cuff bladder encircling at least 80 percent of the arm) was used to ensure accuracy. At least two measurements were made. SBP was the point at which the first of two or more sounds is heard (phase 1), and DBP was the point before the disappearance of sounds (phase 4).

\section{Statistical Analysis}

Data were presented as frequency, percentages, mean, and standard deviation. Categorical variables were compared using Chi Square test. Quantitative variables were compared using Independent t-test. $\mathrm{P}$ value $<0.05$ was considered significant. Statistical analysis was performed using SPSS v21.0 (IBM, USA).

\section{RESULTS}

Retinopathy

A total of 100 patients were included in the study. Out of 100 patients, $30 \%$ patients had retinopathy; $21 \%$ had hypertensive retinopathy ( $5 \%$ patients had grade 1 hypertensive retinopathy, $12 \%$ patients had grade 2 hypertensive retinopathy, and $4 \%$ patients had grade 3 hypertensive retinopathy) while $9 \%$ had bilateral non- proliferative diabetic retinopathy (NPDR) with hypertensive retinopathy (Figure 1).

\section{General Characteristics}

The patients with retinopathy were comparable in age with 
non-retinopathy patients, had no sex-based difference, body mass index (BMI), diet pattern, smoking and alcohol consumption were comparable. However, there was a significant higher number of retinopathy patients were diabetic $(\mathrm{P}=0.003)$ (Table 1 ).

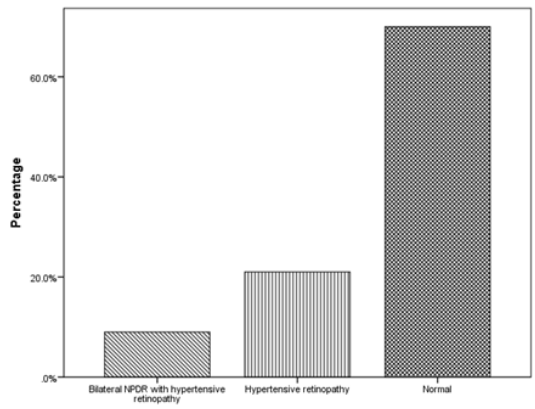

Figure 1: Retinopathy

Table 1: Comparison Of General Characteristics Among Retinopathy And Non-retinopathy Patients

\begin{tabular}{|l|l|l|l|}
\hline & $\begin{array}{l}\text { Retinopathy } \\
(\mathbf{n}=\mathbf{3 0})\end{array}$ & $\begin{array}{l}\text { No retinopathy } \\
(\mathbf{n}=\mathbf{7 0})\end{array}$ & P value \\
\hline Age (years) & $72.7 \pm 7.9$ & $70.1 \pm 6.2$ & 0.082 \\
\hline Male sex, $\mathbf{n}$ & 17 & 35 & 0.541 \\
\hline BMI $\left(\mathbf{K g} / \mathbf{m}^{2}\right)$ & $24.1 \pm 2.3$ & $23.4 \pm 2.4$ & 0.234 \\
\hline Non-veg diet, $\mathbf{n}$ & 12 & 27 & 0.893 \\
\hline Smoking & 2 & 21 & 0.330 \\
\hline Alcohol & 10 & 13 & 0.108 \\
\hline Diabetes & 11 & 8 & 0.003 \\
\hline
\end{tabular}

Association With Laboratory Investigations

There were a significantly higher proportion of retinopathy in the patients with chronic kidney disease $(\mathrm{P}=0.003)$. There were a significant number of patients with dyslipidemia among retinopathy patients $(\mathrm{P}<0.05)$ (Table 2$)$

\begin{tabular}{|l|l|l|l|}
\hline & $\begin{array}{l}\text { Retinopathy } \\
(\mathrm{n}=30)\end{array}$ & $\begin{array}{l}\text { No retinopathy } \\
(\mathrm{n}=70)\end{array}$ & P value \\
\hline Creatinine $>1.4$ & 8 & 4 & 0.003 \\
\hline Cholesterol $>230$ & 14 & 11 & 0.001 \\
\hline Triglycerides $>160$ & 12 & 10 & 0.004 \\
\hline LDL $>120$ & 11 & 11 & 0.020 \\
\hline
\end{tabular}

Retinopathy With Type Of Stage Of Hypertension

Stage I included the patients whose blood pressure was between 140-159 mmHg. Stage II included patients having blood pressure above $160 \mathrm{mmHg}$. In stage 1 hypertension, none of the patients had hypertensive retinopathy while $3 \%$ patients of bilateral NPDR were in stage-l hypertension. All of the patients with hypertensive retinopathy had stage-2 hypertension, while $6 \%$ patients with bilateral NPDR had stage-2 hypertension (table 3).

Table 3: Retinopathy In Different Stage Of Hypertension

\begin{tabular}{|l|l|l|l|}
\hline & $\begin{array}{l}\text { Stage 1 } \\
(\mathbf{n}=\mathbf{2 8})\end{array}$ & $\begin{array}{l}\text { Stage 2 } \\
(\mathbf{n}=\mathbf{7 2})\end{array}$ & $\begin{array}{l}\text { Total } \\
(\mathbf{n}=100)\end{array}$ \\
\hline $\begin{array}{l}\text { Hypertensive retinopathy } \\
\text { Grade 1 }\end{array}$ & 0 & 21 & 21 \\
Grade 2 & 0 & 5 & 5 \\
Grade 3 & 0 & 12 & 12 \\
\hline $\begin{array}{l}\text { Bilateral NPDR with } \\
\text { hypertensive retinopathy }\end{array}$ & 3 & 4 & 4 \\
\hline Normal & 25 & 45 & 9 \\
\hline
\end{tabular}

\section{DISCUSSION}

Retinal microvascular abnormalities (e.g., microaneurysms, focal and generalized arteriolar narrowing, and arteriovenous nicking) seem to be relatively common findings in adult persons, even in those without diabetes. ${ }^{9}$ In the Beaver Dam Eye Study, these lesions were detected in $2 \%$ to $14 \%$ of the nondiabetic population 43 to 86 years of age ${ }^{10}$, with incident lesions developing in $6 \%$ to $10 \%$ of this population after 5 years. ${ }^{11}$ In the Atherosclerosis Risk in Communities (ARIC) study, retinal microvascular abnormalities were found in $3 \%$ to $8 \%$ of nondiabetic persons 48 to 72 years of age. ${ }^{12}$ In our study, $30 \%$ patients were found to have retinopathy.

The cause, systemic associations, and clinical significance of these retinal abnormalities are not fully understood. ${ }^{9,13}$ Several studies have shown that these lesions are associated with presence and severity of hypertension. In our study, we found that $27 \%$ of retinopathy were in stage 2 hypertension. Following an increase in blood pressure, the microcirculation of the retina will be damaged to varying degrees. However, the risk of retinopathy is reduced if blood pressure is controlled effectively.

Dyslipidemia in hypertensive patients is itself known to be a predisposing risk factor, an aggravating or complicating factor. Hypertension and hyperlipidemia not only accelerate atherogenesis but also cause degenerative changes in the walls of large- and medium-sized arteries, which accelerate cerebrovascular hemorrhage, ischemic heart disease, stroke, and cardiac arrest. In this study, we found that dyslipidemia was significantly associated with retinopathy. Gupta et al showed that the increasing level of serum LDL-cholesterol had statistically significant correlation with the grades of hypertensive retinopathy $(\mathrm{P}<0.0001)$.

Mean triglycerides levels were also found to be high in grade II and higher hypertensive retinopathy patients in a study carried out by Bastola et al. ${ }^{16}$

\section{CONCLUSION}

There is a significant prevalence of retinopathy among newly diagnosed elderly hypertensive patients. Diabetes, dyslipidemia, CKD, and increased grade of hypertension was associated with retinopathy.

\section{REFERENCES}

1. Chobanian AV. Control of hypertension-an important national priority. [Editorial] N Engl J Med 2001;345:534-5.

2. Wolf-Maier K, Cooper RS, Banegas JR, et al. Hypertension prevalence and blood pressure levels in 6 European countries, Canada, and the United States. JAMA 2003;289:2363-9.

3. Gorelick PB. New horizons for stroke prevention PROGRESS and HOPE. Lancet Neurology 2002;1:149-56.

4. Wolf-Maier K, Cooper RS, Kramer, et al. Hypertension treatment and control in five European countries, Canada, and the United States. Hypertension 2004:43:10-17

5. Giampaoli S, Palmieri L, Chiodini P, et al. The global cardiovascular risk chart. Ital Heart J Suppl 2004;5:177-85.

6. Kabedi NN, Mwanza JC, Lepira FB, Kayembe TK, Kayembe DL. Hypertensive retinopathy and its association with cardiovascular, renal and cerebrovascular morbidity in Congolese patients. Cardiovasc J Afr. 2014 SepOct;25(5):228-32.

7. Henderson $A D$, Bruce BB, Newman NJ, Biousse V. Hypertension-related eye abnormalities and the risk of stroke. Rev Neurol Dis. 201 1;8(1-2):1-9.

8. Erden S, Bicakci E. Hypertensive retinopathy: incidence, risk factors, and comorbidities. Clin. Exp. Hypertens. 2012;34(6):397-401

9. Karter Y, Curgunlu A, Altinisik S, et al. Target organ damage and changes in arterial compliance in white coat hypertension. Is white coat innocent? Blood Press 2003;12:307-13

10. Wong TY, Klein R, Klein BEK, et al. Retinal microvascular abnormalities and their relationship with hypertension, cardiovascular disease, and mortality. Surv Ophthalmol 2001;46: 59-80.

11. Klein R, Klein BEK, Moss SE, Wang Q. Hypertension and retinopathy, arteriolar narrowing, and arteriovenous nicking in a population. Arch Ophthalmol 1994;112:92-8.

12. Klein R, Klein BEK, Moss SE. The relation of systemic hypertension to changes in the retinal vasculature. The Beaver Dam Eye Study. Trans Am Ophthalmol Soc 1997:95:329-48 discussion 348-50.

13. Klein R, Sharrett AR, Klein BEK, et al. Are retinal arteriolar abnormalities related to atherosclerosis? The Atherosclerosis Risk in Communities Study. Arterioscler Thromb Vasc Biol 2000;20:1644-50.

14. Tso MOM, Jampol LM. Pathophysiology of hypertensive retinopathy. Ophthalmology 1982;89:1132-45

15. Gupta RP, Gupta S, Gahlot A, Sukharamwala D, Vashi J. Evaluation of hypertensive retinopathy in patients of essential hypertension with high serum lipids. Med J DY Patil Univ 2013;6:165-9

16. Bastola P, Pun CB, Koirala S, Shrestha UK. Fasting serum lipids and fundus changes in hypertensive patients. Nepal J Med Sci 2012;1:103-7 